\title{
Avaliação de substratos orgânicos na produção de mudas de hortelã (Mentha gracilis R. Br. e Mentha x villosa Huds.)
}

\author{
PAULUS, D. ${ }^{1 *}$; VALMORBIDA, R. ${ }^{1}$; TOFFOLI, E. ${ }^{1}$; PAULUS, E. ${ }^{2}$; GARLET, T.M.B. ${ }^{3}$ \\ ${ }^{1}$ UTFPR - Campus Dois Vizinhos, Estrada para Boa Esperança, Caixa postal 157, CEP: 85660-000, Dois \\ VizinhosBrasil *dalvapaulus@utfpr.edu.br ${ }^{2}$ UFSM - Departamento de Solos, Avenida Roraima, 1000, Cidade \\ Universitária, Bairro Camobi, CEP: 97105-900, Santa Maria-Brasil' ${ }^{3}$ UNICRUZ-Departamento de Ciências Biológicas, \\ Rua Andrade Neves, 308, CEP: 98025-810, Cruz Alta-Brasil
}

\begin{abstract}
RESUMO: A determinação de substratos alternativos viáveis para a produção de mudas de plantas medicinais é de grande relevância, pois o aproveitamento de resíduos de atividades agrícolas representa alternativa para problemas ambientais e sociais. Os experimentos foram realizados em ambiente protegido e a campo, na Universidade Tecnológica Federal do Paraná, Campus Dois Vizinhos, com o objetivo de avaliar substratos orgânicos para produção de mudas de hortelã para cultivo a campo. O delineamento experimental foi blocos casualizados, com três repetições, em esquema fatorial, sendo avaliados quatro substratos [esterco bovino + vermiculita + areia (1:1:1), esterco bovino + areia + solo (1:1:1), solo + vermiculita + cama-de-aviário (1:1:1) e substrato organo-mineral Plantmax $® \mathrm{HA}$ ] e duas espécies de menta (Mentha gracilis e Mentha $x$ villosa). Foram analisadas a altura da plantas e o número de folhas aos 07,14 e 21 dias após o transplantio, índice de mortalidade, massa fresca e seca da parte aérea e das raízes. Não houve interação entre as espécies de menta e substratos para as variáveis analisadas. O substrato organo-mineral Plantmax $\AA$ apresentou os melhores resultados para o número de folhas $(8,44)$, altura $(8,46 \mathrm{~cm})$, produção de massa fresca $\left(1,56 \mathrm{~g}_{\text {planta- }}{ }^{-1}\right)$, seca $\left(0,23 \mathrm{~g} \mathrm{planta}^{-1}\right)$ e $100 \%$ de pegamento de mudas a campo o que para o produtor de menta é de grande interesse. Com base nos resultados obtidos, pode-se concluir que para a produção de mudas de Mentha gracilis e Mentha villosa o substrato Plantmaxâ HA é o mais recomendado.
\end{abstract}

Palavras-chave: Mentha gracilis, Menthax villosa, plantas medicinais, substratos

\begin{abstract}
Evaluation of organic substrates on mint (Mentha gracilis $\mathrm{R}$. Br. and Mentha $\mathbf{X}$ villosa Huds.) seedling production. The determination of viable alternative substrates is of great importance for the production of medicinal seedlings since the use of residues from agricultural activities represents an alternative to solve environmental and social problems. The experiments were carried out in protected environment and in the field, located in the Federal Technological University of Paraná, Dois Vizinhos Campus, Paraná State, Brazil. The aim of this work was to evaluate organic substrates for the production of mint seedlings in the field. Experimental design was in randomized blocks, with three replicates, in a factorial arrangement evaluating four substrates [bovine manure + vermiculite + sand (1:1:1); bovine manure + sand + soil (1:1:1); soil + vermiculite + poultry manure (1:1:1); and the organomineral substrate Plantmax $\left.{ }^{\circledR} \mathrm{HA}\right]$ and two mint species (Mentha gracilis and Menthax villosa). Plant height and leaf number were evaluated at 07, 14 and 21 days after transplanting, besides death rate and fresh and dry matter of shoots and roots. There was no interaction between mint species and substrates for the evaluated variables. The organomineral substrate Plantmax $®$ HA presented the best results for leaf number (8.44), height $(8.46 \mathrm{~cm})$, fresh matter $\left(1.56 \mathrm{~g} \mathrm{plant}^{-1}\right)$, dry matter $\left(0.23 \mathrm{~g} \mathrm{plant}^{-1}\right)$ and set $(100 \%$ seedlings in the field), which is of great interest for the mint producer. Based on these results, we concluded that the substrate Plantmaxâ HA is the most recommended for the production of Menthax villosa and Mentha gracilis seedlings.
\end{abstract}

Key words: Mentha gracilis, Menthax villosa, medicinal plants, substrates

Recebido para publicação em 19/08/2009

Aceito para publicação em 07/07/2010

Rev. Bras. Pl. Med., Botucatu, v.13, n.1, p.90-97, 2011. 


\section{INTRODUÇÃO}

Espécies de Mentha têm sido investigadas tanto pelas atividades biológicas como pelos óleos essenciais produzidos pelas folhas. As espécies Mentha gracilis e Mentha $\mathrm{x}$ villosa são plantas medicinais e aromáticas cultivadas em todo o Brasil, sendo largamente utilizadas por indústrias químicas, farmacêuticas, de cosméticos e de alimentos (Paulus et al., 2005).

Dentre os fatores importantes para serem avaliados no processo de produção de mudas de boa qualidade, encontram-se os substratos. Para Kämpf (2001), a escolha do substrato e o correto manejo são sérios problemas técnicos para os viveiristas, devido à importância da obtenção de mudas de qualidade. Assim, o uso do substrato adequado é um dos fatores fundamentais para a produção de mudas que garante o estabelecimento do plantio, reduz o tempo de formação e as perdas em campo (Vieira et al., 1998).

Para que o substrato seja considerado adequado para o enraizamento devem ser consideradas algumas características importantes, como a capacidade de sustentar as estacas durante todo o processo, proporcionar umidade e permitir aeração nas bases (Ming et al., 1998). Para possibilitar o crescimento e a atividade do sistema radicular de plantas, entre outras propriedades físicas e químicas, um substrato agrícola deve reter água sem diminuir a disponibilidade de oxigênio para as raízes. O oxigênio é indispensável para a respiração, a fim de suprir a energia necessária à absorção dos nutrientes (Salsac et al., 1987).

Ribeiro (1998) sugere que o substrato para produção de mudas deve possuir equilíbrio entre matéria mineral, matéria orgânica, ar e água. Em termos práticos, o substrato deve reter umidade, ser poroso o suficiente para garantir boa aeração e boa drenagem, ser livre de sementes de plantas invasoras, nematóides e patógenos, e fornecer os nutrientes essenciais ao crescimento das mudas. Além disso, precisa fornecer a fixação da planta e a qualidade deve permanecer a mesma por longo período, a fim de que o processo do sistema de cultivo possa ser padronizado (Röber, 2000).

Os materiais para composição dos substratos devem ser facilmente disponíveis na região, possuir baixo custo e que forneçam as condições físicoquímicas adequadas ao crescimento das plantas (Vieira et al., 1998).

No Brasil, o esterco animal misturado ao solo tem sido muito usado como substrato para a produção de mudas. Gonçalves et al. (2000) citam que o substrato básico para obtenção de mudas em tubetes é do tipo orgânico como o esterco de curral curtido. O esterco bovino faz parte também da composição do substrato mais utilizado para a produção de mudas de cafeeiro (Coffea arabica L.)
(Andrade Neto, 1999) e mangabeira (Hancornia speciosa G.) (Fernandez, 2002).

Com relação à utilização da areia na mistura de substratos Fachinello et al. (1994) citam que também é material que pode fazer parte do substrato para produção de mudas, por ser de baixo custo, fácil disponibilidade e principalmente por permitir boa drenagem. Esta é importante para melhorar a condição de aeração do substrato (Lima et al., 2003). Contudo, Campos et al. (1986) observaram que a mesma é pobre em nutrientes.

A utilização de solo natural ou da mistura de solo com areia ainda é prática rotineira dos viveiristas de mudas frutíferas e flores, pela grande disponibilidade e baixo custo (Gauland, 1997). Porém, estes substratos podem apresentar inconvenientes no crescimento destas plantas, quando utilizados como substrato único, tornando-se necessária a busca de materiais alternativos que permitam melhorar as condições dos substratos sem aumentar demasiadamente o custo.

O substrato organo-mineral Plantmax ${ }^{\circledR}$ elaborado à base de vermiculita expandida e material orgânico possuem macro e micronutrientes necessários ao desenvolvimento inicial das mudas, boas características físicas, boa capacidade de retenção de água e é livre de pragas e doenças (Lopes, 1996).

A forma usual para produção de mudas de menta a campo é a utilização de estolões. Com essa técnica a porcentagem de pegamento é menor e a muda muitas vezes de qualidade inferior, resultando em desuniformidade e menor rendimento de plantas no campo (Paulus \& Paulus, 2007). A pesquisa para produção de mudas de menta, envolvendo o uso de substratos, torna-se necessária, como alternativa de reduzir custos na propriedade e viabilizar o uso de materiais disponíveis para a produção de mudas de hortelã. A região Sudoeste do Paraná apresenta como cenário agrícola, pequenas propriedades, onde a avicultura e a bovinocultura de leite são as principais atividades desenvolvidas. Como subproduto dessas atividades, a cama-de-aviário e o esterco bovino podem ser utilizados para o preparo de substratos, sendo materiais de disponibilidade na região.

Desta forma, o presente trabalho teve como objetivo avaliar substratos orgânicos visando à produção de mudas de hortelã para cultivo a campo.

\section{MATERIAL E MÉTODO}

Os experimentos foram realizados em duas etapas, a produção de mudas em tubetes em ambiente protegido e o desenvolvimento no solo a campo, no período de setembro a novembro de 2008, em área experimental da Universidade Tecnológica Federal do Paraná (UTFPR - Campus Dois Vizinhos). Avaliaram-se as características físicas e

Rev. Bras. Pl. Med., Botucatu, v.13, n.1, p.90-97, 2011. 
químicas dos substratos. As determinações das características físicas e químicas foram realizadas seguindo metodologia descrita na Instrução Normativa № 14 (IN 14), de 15 de dezembro de 2004, do Ministério da Agricultura, Pecuária e Abastecimento, que trata das Definições e Normas sobre as Especificações e as Garantias, as Tolerâncias, o Registro, a Embalagem e a Rotulagem dos Substratos para Plantas.

O solo de superfície utilizado para mistura dos substratos foi classificado como Latossolo Vermelho. Acama-de-aviário foi utilizada após passar por processo de fermentação de dois meses, sendo oriunda de seis lotes de frangos, produzida no Campus da Universidade. O esterco de bovino foi utilizado após estar decomposto.

As plantas matrizes utilizadas para obtenção das estacas foram cultivadas em canteiros na horta medicinal da UTFPR. As estacas foram retiradas com quatro folhas e $4 \mathrm{~cm}$ de comprimento, do ápice das plantas matrizes. Posteriormente, foi enraizada uma muda por tubete com dimensões de diâmetro de bocal de $38 \mathrm{~mm}$, oito estrias, altura de $120 \mathrm{~mm}$ e volume de $80 \mathrm{~cm}^{3}$, contendo os diferentes substratos. Os tubetes foram organizados em grade de arame suporte, de forma suspensa, sob ambiente protegido. As irrigações foram realizadas com regador, três vezes ao dia.

O delineamento experimental foi blocos ao acaso, com três repetições em esquema fatorial, sendo estudados os efeitos de quatro substratos [solo + vermiculita + cama-de-aviário (1:1:1); esterco bovino + areia + solo (1:1:1) e esterco bovino + areia + vermiculita (1:1:1); e organo-mineral Plantmax ${ }^{\circledR} \mathrm{HA}$ ] e duas espécies de menta (Mentha gracilis e Mentha $x$ villosa). Foram utilizadas 15 estacas de cada espécie por tratamento.

As observações de altura das mudas, número de folhas e índice de mortalidade foram realizadas aos sete, 14 e 21 dias após a introdução das estacas nos substratos, em ambiente protegido.
Posteriormente, foi feito o transplantio a campo, para verificar o pegamento das mudas. A determinação da massa fresca da parte aérea foi realizada aos 33 DAT (Dias após o transplantio), não se determinou a massa fresca das raízes em função delas terem sido lavadas e apresentarem excesso de água, o que levaria ao erro na determinação da massa fresca. As raízes e a parte aérea foram separadas e colocadas em estufa com circulação de ar forçada a $65^{\circ} \mathrm{C}$ para obtenção da massa seca das raízes e da parte aérea. Os dados foram submetidos à análise da variância, utilizando-se o programa estatístico SAS (SAS, Institute, 1999) sendo as médias comparadas pelo teste de Tukey a $5 \%$ de significância.

\section{RESULTADO E DISCUSSÃO}

Com relação à umidade gravimétrica observou-se que o substrato esterco bovino + vermiculita + areia apresentou o menor valor $(9,74 \%)$, enquanto que o substrato organo-mineral Plantmaxâ os maiores valores (113\%) (Tabela 1). As densidades dos substratos variaram de 0,44 a $1,0 \mathrm{~g} \mathrm{~cm}^{3}$. $\mathrm{O}$ substrato organo-mineral Plantmax ${ }^{\circledR}$ apresentou 0 menor valor e o substrato esterco bovino + areia + solo o maior valor desse atributo físico.

Os valores da porosidade total dos substratos analisados variaram de 57,4 a $78 \%$. Pode-se observar que o substrato organo-mineral Plantmax ${ }^{\circledR}$ que apresentou maior porosidade, também demonstrou maior capacidade de retenção de água (66\%). Os substratos, com exceção do Plantmaxâ, encontram-se abaixo do ideal de porosidade, que está em torno de 70 a 85\% (Milner, 2002). Para favorecer o equilíbrio entre a aeração e a retenção de umidade, o ideal é utilizar substratos de densidade total baixa e alta porosidade.

Schmitz et al. (2002), avaliando as características físicas de diversos substratos, constataram que materiais minerais, como solo e areia, possuem excessiva densidade e reduzida porosidade, sendo deficientes em aeração. Isso foi constatado na

TABELA 1. Características físicas dos substratos avaliados para produção de mudas de hortelã quanto à umidade gravimétrica (\%), densidade $\left(\mathrm{g} \mathrm{cm}^{-3}\right)$, porosidade total (\%) e capacidade de retenção de água (\%) à tensão de 10 hPa. UTFPR, Campus Dois Vizinhos, setembro de 2008.

\begin{tabular}{lcccc}
\hline \multicolumn{1}{c}{ Substrato } & $\begin{array}{c}\text { Umidade } \\
\text { gravimétrica } \\
(\%)\end{array}$ & $\begin{array}{c}\text { Densidade } \\
\left(\mathrm{g} \mathrm{cm}^{-3}\right)\end{array}$ & $\begin{array}{c}\text { Porosidade } \\
\text { total } \\
(\%)\end{array}$ & $\begin{array}{c}\text { Capacidade de } \\
\text { retenção de água } \\
\%\end{array}$ \\
\hline $\begin{array}{l}\text { Solo + Vermiculita + Cama-de-aviário } \\
(1: 1: 1)\end{array}$ & 37,02 & 0,59 & 65,2 & 48 \\
Esterco bovin o + areia + so lo (1:1:1) & 14,70 & 1,0 & 59,3 & 49 \\
Esterco bovino + areia + vermiculita (1:1:1) & 9,74 & 0,86 & 57,4 & 52 \\
Substrato organo-mineral Plantmax ${ }^{\circledR}$ HA & 113 & 0,44 & 78,0 & 66 \\
\hline
\end{tabular}

Rev. Bras. Pl. Med., Botucatu, v.13, n.1, p.90-97, 2011. 
análise física dos substratos contendo areia e solo, que proporcionou reduzido espaço poroso total.

Analisando as características químicas dos substratos, o valor de $\mathrm{pH}$ é muito importante, pois valores baixos podem incrementar a disponibilidade de alguns micronutrientes e causar fitotoxidade para algumas plantas. Dessa forma, entre valores de $\mathrm{pH}$ de 6,0 e 7,0 ocorre adequada disponibilidade de nutrientes nos substratos minerais. Para substratos orgânicos, esse valor varia de 5,2 a 5,5 (Kampf, 2000). Com base nesses fundamentos, os substratos apresentaram valores próximos ao considerado adequado (Tabela 2). Entretanto, apresentaram altos valores de nutrientes e saturação por bases, que propiciaram adequado crescimento das plantas.

Não houve interação entre substratos e espécies de menta para as variáveis analisadas. Para a altura das mudas aos sete, 14 e 21 dias após o transplantio, na fase de produção de mudas nos diferentes substratos, verificou-se que o melhor substrato foi o organo-mineral Plantmax ${ }^{\circledR}$ (Tabela 3). Os substratos solo + vermiculita + cama-de-aviário, esterco bovino + areia + solo e esterco + vermiculita + areia não diferiram estatisticamente entre si aos sete, 14 e 21 dias após o transplantio. Com exceção do substrato esterco bovino + areia + solo aos 21 dias, que diferiu dos outros dois substratos.

Com relação às médias dos tratamentos, observou-se evolução no ganho em altura, sendo que, na fase inicial obteve-se um ganho de $1,74 \mathrm{~cm}$ aos 14 (DAT) e 2,48 cm aos 21 dias após o transplantio. Os valores de ganho em altura indicam que os substratos utilizados resultaram em acréscimo de $67 \%$ para o crescimento das mudas em altura.

Nas condições em que o presente estudo foi desenvolvido verificou-se que houve diferença entre o número de folhas aos sete, 14 e 21 após transplante, sendo que o Plantmaxâ foi o melhor substrato (Tabela 4). Os demais tratamentos avaliados não diferiram estatisticamente entre si, com exceção do substrato esterco + vermiculita + areia aos 21 dias, que não diferiu do substrato Plantmaxâa HA. Constatou-se acréscimo do número de folhas nos intervalos de tempo avaliados, sendo de 2,28 $\mathrm{cm}$ e $1,4 \mathrm{~cm}$ aos 14 e 21 DAT, respectivamente. Esse acréscimo no número de folhas indica que os substratos utilizados contribuíram, de forma positiva, para o crescimento das mudas.

As espécies estudadas, com exceção da altura aos 14 DAT, não diferiram quanto à variável altura de mudas e número de folhas avaliadas nos diferentes substratos (Tabela 5). É interessante observar que

TABELA 2. Características químicas dos substratos avaliados para produção de mudas de hortelã. UTFPR, Dois Vizinhos, 2008.

\begin{tabular}{|c|c|c|c|c|}
\hline Análise química & $\begin{array}{c}\text { Solo + Vermiculita + } \\
\text { Cama-de-aviário } \\
(1: 1: 1)\end{array}$ & $\begin{array}{l}\text { Esterco bovino } \\
+ \text { areia + solo. } \\
\qquad(1: 1: 1)\end{array}$ & $\begin{array}{c}\text { Esterco bovino + } \\
\text { areia }+ \text { vermiculita } \\
(1: 1: 1)\end{array}$ & $\begin{array}{c}\text { Substrato organo- } \\
\text { mineral Plantmax } \\
\text { HA }\end{array}$ \\
\hline M.O $\left(\mathrm{g} \mathrm{dm}^{-3}\right)$ & 73,7 & 50,93 & 50,93 & 134,02 \\
\hline$P-\mathrm{mg} \mathrm{dm}^{-3}$ & 205,5 & 183,63 & 128,24 & 105,88 \\
\hline $\mathrm{K}-\mathrm{cmol}_{\mathrm{c}} \mathrm{dm}^{-3}$ & 4,2 & 2,25 & 1,8 & 0,63 \\
\hline $\mathrm{Cu}-\mathrm{mg} \mathrm{dm}^{-3}$ & 2,2 & 3,83 & 1,7 & 1,09 \\
\hline $\mathrm{Fe}-\mathrm{mg} \mathrm{dm}^{-3}$ & 14,7 & 35,25 & 62,21 & 210,43 \\
\hline $\mathrm{Zn}-\mathrm{mg} \mathrm{dm}^{-3}$ & 17,1 & 5,82 & 3,57 & 3,79 \\
\hline $\mathrm{Mn}-\mathrm{mg} \mathrm{dm}^{-3}$ & 221,3 & 134,91 & 65,61 & 57,96 \\
\hline $\mathrm{pH} \mathrm{CaCl} 2$ & 4,6 & 6,6 & 7 & 5,4 \\
\hline SMS índice & 7,4 & 7,0 & 7,6 & 5,9 \\
\hline $\mathrm{Al}^{+3} \mathrm{cmol}_{\mathrm{c}} \mathrm{dm}^{-3}$ & 0 & 0 & 0 & 0 \\
\hline $\mathrm{H}+\mathrm{AL} \mathrm{cmol} \mathrm{dm}^{-3}$ & 1,2 & 2,07 & 1,22 & 5,47 \\
\hline $\mathrm{Ca} \mathrm{cmol} \mathrm{dm}^{-3}$ & 6,8 & 6,39 & 5,39 & 11,049 \\
\hline $\mathrm{Mg} \mathrm{cmol}_{\mathrm{C}} \mathrm{dm}^{-3}$ & 6,2 & 3,24 & 5,14 & 8,45 \\
\hline $\mathrm{SB} \mathrm{cmol}_{\mathrm{C}} \mathrm{dm}^{-3}$ & 17,1 & 11,88 & 12,33 & 20,57 \\
\hline V (\%) & 92,2 & 85,16 & 91 & 78,99 \\
\hline Sat. Al (\%) & 0 & 0 & 0 & 0 \\
\hline CTC $\mathrm{cmol}_{\mathrm{c}} \mathrm{L}^{-1}$ & 18,59 & 14 & 13,55 & 26,04 \\
\hline
\end{tabular}

Rev. Bras. Pl. Med., Botucatu, v.13, n.1, p.90-97, 2011. 
TABELA3. Altura de plantas de Mentha gracilis e Menthax villosa produzidas em tubetes com diferentes substratos, em ambiente protegido. UTFPR, Dois Vizinhos, 2008.

\begin{tabular}{cccc}
\hline & \multicolumn{3}{c}{ Altura (cm) } \\
\cline { 2 - 4 } Substratos & 7 & 14 & 21 \\
\hline Solo + vermiculita + cama-de-aviário & $1,91 \mathrm{~b}^{*}$ & $3,13 \mathrm{~b}$ & $5,37 \mathrm{~b}$ \\
Esterco bovino + areia + solo & $2,05 \mathrm{~b}$ & $3,26 \mathrm{~b}$ & $4,83 \mathrm{c}$ \\
Esterco + vermiculita + areia & $1,85 \mathrm{~b}$ & $3,78 \mathrm{~b}$ & $6,67 \mathrm{~b}$ \\
Organo-mineral Plantmax ${ }^{\circledR} \mathrm{HA}$ & $2,63 \mathrm{a}$ & $5,24 \mathrm{a}$ & $8,46 \mathrm{a}$ \\
\hline Média & 2,11 & 3,85 & 6,33 \\
\hline CV\% & 16 & 13 & 18 \\
\hline
\end{tabular}

*Médias seguidas das mesmas letras, nas colunas, não diferem estatisticamente pelo teste de Tukey a $5 \%$ de probabilidade.

TABELA 4. Número de folhas por planta de Mentha x gracilis e Menthax villosa produzidas em tubetes com quatro substratos, em ambiente protegido. UTFPR, Dois Vizinhos, 2008.

\begin{tabular}{lccc}
\hline \multirow{2}{*}{ Substratos } & \multicolumn{3}{c}{ Número de folhas } \\
\hline Solo + vermiculita + cama-de-aviário & 7 & 14 & 21 \\
Esterco bovino + areia + solo & $3,53 b^{*}$ & $5,61 \mathrm{~b}$ & $7,00 \mathrm{~b}$ \\
Esterco + vermiculita + areia & $3,61 \mathrm{~b}$ & $5,19 \mathrm{~b}$ & $6,11 \mathrm{~b}$ \\
Organo-mineral Plantmax ${ }^{\circledR} \mathrm{HA}$ & $3,50 \mathrm{~b}$ & $6,03 \mathrm{~b}$ & $8,28 \mathrm{a}$ \\
\hline Média & $4,47 \mathrm{a}$ & $7,42 \mathrm{a}$ & $8,44 \mathrm{a}$ \\
\hline CV\% & 3,78 & 6,06 & 7,46 \\
\hline
\end{tabular}

*Médias seguidas das mesmas letras, nas colunas, não diferem estatisticamente pelo teste de Tukey, a 5\% de probabilidade.

TABELA 5. Altura de mudas e número de folhas de Mentha gracilis e Menthax villosa produzidas em tubetes com quatro substratos em ambiente protegido. UTFPR, Dois Vizinhos, 2008.

\begin{tabular}{lcccccc}
\hline Espécies & \multicolumn{3}{c}{ Altura $(\mathrm{cm})$} & & No de folhas \\
& 7 DAT & 14 DAT & 21 DAT & 7 DAT & 14 DAT & 21 DAT \\
\hline Mentha gracilis & $2,16 \mathrm{a}^{*}$ & $4,18 \mathrm{a}$ & $6,46 \mathrm{a}$ & $3,92 \mathrm{a}$ & $6,08 \mathrm{a}$ & $7,58 \mathrm{a}$ \\
Mentha villosa & $2,07 \mathrm{a}$ & $3,52 \mathrm{~b}$ & $6,20 \mathrm{a}$ & $3,64 \mathrm{a}$ & $6,04 \mathrm{a}$ & $7,33 \mathrm{a}$ \\
\hline
\end{tabular}

para a produção de mudas de menta em tubetes, as duas espécies se adaptaram aos diferentes substratos, sendo que as mudas apresentaram folhas com coloração verde escuro e o sistema radicular adequado e saudável, de coloração clara, sem sinais de deficiência de oxigênio.

Paulus \& Paulus (2007), em trabalhos de avaliação de três tipos de substratos (organo mineral; casca de arroz carbonizada + solo e casca de arroz carbonizada + areia) para produção de mudas de Mentha arvensis em tubetes, constataram que 0 substrato organo-mineral apresentou os melhores resultados em relação à altura, número de folhas e massa fresca e seca tanto em ambiente protegido quanto na fase de desenvolvimento a campo.
Com relação à mortalidade das mudas no ambiente protegido, o substrato solo + vermiculita + cama-de-aviário resultou em maior mortalidade (\%) 2,5, 12,5 e 20 aos sete, 14 e 21 DAT (Tabela 6), possivelmente devido às características físicas, por ser substrato denso e com baixa capacidade de retenção de água. Os demais substratos não diferiram entre si.

Na produção de massa fresca e seca da parte aérea e raízes observou-se que o substrato Plantmax ${ }^{\circledR}$ foi superior aos demais tratamentos (Tabela 7). As mudas produzidas em Plantmax ${ }^{\circledR}$ proporcionaram 0,90 g planta-1 de massa fresca a mais que o substrato composto por esterco bovino + areia + solo, que apresentou o menor valor (0,66 g planta- $\left.{ }^{-1}\right)$. A espécie Menthax villosa apresentou valores superiores (12\% 
e $29 \%$ ) para massa fresca e massa seca da parte aérea, respectivamente, e $22 \%$ de massa seca das raízes em relação à Mentha gracilis (Tabela 7).

Os excelentes resultados obtidos com o substrato Plantmax ${ }^{\circledR}$ foram provavelmente em função das características físicas e químicas, principalmente por ser menos denso $\left(0,44 \mathrm{~g} \mathrm{~cm}^{-3}\right)$, maior porosidade total $(78 \%)$ e valor mais elevado de CTC $(26,04)$, o que proporcionou maior capacidade de armazenamento e de fornecimento dos nutrientes as plantas. $O$ substrato esterco bovino + areia + solo apresentou menor crescimento e desenvolvimento, devido à maior densidade $\left(1,0 \mathrm{~g} \mathrm{~cm}^{-3}\right)$, em função da areia apresentar menor capacidade de armazenamento de água por unidade de volume e de massa úmida.

Analisando os resultados da CTC dos substratos estudados e comparando estes com as espeficificações de Penningsfeld (1983) onde a faixa ideal (>12), todos os substratos apresentaram valores de CTC superiores à faixa ideal. As propriedades químicas e físicas dos substratos variam em função da constituição, granulometria e compactação do substrato (Santos et al., 2002). Ainda, nesse aspecto, deve-se considerar que é difícil encontrar um único material que atenda todas as características físicas e nutricionais exigidas pelas mudas, por isso é necessário fazer a mistura de vários materiais/ componentes diferentes e selecionar a melhor combinação, para atender tais exigências, levando em conta também à disponibilidade e custo.

Resultados semelhantes foram obtidos por Lopes (1996) em trabalho de propagação sexuada de mudas de maracujazeiro em tubetes, com uso de diferentes substratos e doses de adubação nitrogenada, que concluiu que o substato organomineral (Plantmax ${ }^{\circledR}$ ) proporcionou melhor desenvolvimento das mudas em comparação com os outros utilizados, com as seguintes composições: a) $70 \%$ de vermiculita $+30 \%$ de terra de subsuperfície; b) $40 \%$ de casca de arroz carbonizada $+30 \%$ de terra de subsuperfície $+30 \%$ de areia.

Durante a realização do transplantio das mudas não se verificaram dificuldades com a retirada das mudas dos tubetes, uma vez que, os substratos proporcionaram

TABELA6. Valores médios de mortalidade de mudas de Mentha gracilis e Menthax villosa avaliadas em tubetes com diferentes tipos de substratos, em ambiente protegido. UTFPR, Dois Vizinhos, 2008.

\begin{tabular}{lccc}
\hline & \multicolumn{2}{c}{ Mortalidade de mudas de menta (\%) } \\
\cline { 2 - 4 } Substratos & 7 DAT & 14 DAT & 21 DAT \\
\hline Solo + vermiculita + cama-de-aviário & $2,5 \mathrm{a}^{*}$ & $12,5 \mathrm{a}$ & $20 \mathrm{a}$ \\
Esterco bovino + areia + solo & $0 \mathrm{~b}$ & $2 \mathrm{~b}$ & $2 \mathrm{~b}$ \\
Esterco + vermi culita+areia & $0,8 \mathrm{~b}$ & $2 \mathrm{~b}$ & $2 \mathrm{~b}$ \\
Organo-mineral Plantmax ${ }^{\circledR} \mathrm{HA}$ & $0 \mathrm{~b}$ & $0 \mathrm{~b}$ & 6 \\
\hline *Médias & 0,8 & 4 & 6 \\
\hline Médias seguidas das mesmas letras, nas colunas, não diferem estatisticamente pelo teste de Tukey, a 5\% de probabilidade.
\end{tabular}

TABELA 7. Massa fresca (MFPA) e seca (MSPA) da parte aérea e das raízes (MSR) ( p planta $^{-1}$ ) de menta (Mentha gracilis e Menthax villosa) avaliadas em tubetes com diferentes substratos, em ambiente protegido. UTFPR, Dois Vizinhos, 2008.

\begin{tabular}{cccc}
\hline Substratos & $\begin{array}{c}\text { MFPA } \\
\left(\text { g planta }^{-1}\right)\end{array}$ & $\begin{array}{c}\text { MSPA } \\
\left(\text { g planta }^{-1}\right)\end{array}$ & $\begin{array}{c}\text { MSR } \\
\left(\text { g planta }^{-1}\right)\end{array}$ \\
\hline Solo + vermiculi ta + cama-de-aviário & $1,00 \mathrm{~b}$ & $0,18 \mathrm{~b}$ & $0,06 \mathrm{c}$ \\
Esterco bovino + areia + solo & $0,66 \mathrm{c}$ & $0,13 \mathrm{c}$ & $0,07 \mathrm{~b}$ \\
Esterco + vermiculita+areia & $1,14 \mathrm{~b}$ & $0,19 \mathrm{~b}$ & $0,08 \mathrm{~b}$ \\
Organo-mineral Plantmax & $1,56 \mathrm{a}$ & $0,23 \mathrm{a}$ & $0,10 \mathrm{a}$ \\
CV\% & 23 & 21 & 19 \\
\hline Espécies & MFPA & MSPA & MSR \\
& $\left(\right.$ g planta $\left.^{-1}\right)$ & $\left(\right.$ g planta $\left.^{-1}\right)$ & $\left(\right.$ g planta $\left.^{-1}\right)$ \\
\hline Mentha gracilis & $1,02 \mathrm{a}$ & $0,15 \mathrm{~b}$ & $0,07 \mathrm{~b}$ \\
Mentha villosa & $1,16 \mathrm{a}$ & $0,21 \mathrm{a}$ & $0,09 \mathrm{a}$ \\
\hline
\end{tabular}

*Médias seguidas das mesmas letras, nas colunas, não diferem estatisticamente pelo teste de Tukey a 5\% de probabilidade. 
a preservação do torrão quando da retirada do recipiente, devido à estabilidade dos agregados dos substratos, principalmente o substrato organo-mineral Plantmax ${ }^{\circledR}$ que se mostrou ser menos denso.

Ao analisar a mortalidade das mudas transplantadas a campo, observou-se que houve diferença significativa entre os substratos avaliados. As mudas produzidas no substrato esterco + vermiculita + areia resultaram em maior mortalidade (10\%) (Tabela 8). Também se verificou que, aos sete dias após o transplantio a campo, ocorreram as mortalidades das mudas, nas avaliações realizadas aos 14 e 21 DAT não ocorreram mortalidades, sendo que o pegamento foi adequado em função do percentual baixo de mortalidade, o que para o produtor de menta é de grande interesse. Também se observou que o sistema radicular das mudas de menta produzidas no substrato Plantmax ${ }^{\circledR}$ desenvolveu-se rapidamente após o transplante a campo, favorecendo melhor estruturação da muda e o pegamento.

TABELA 8. Valores médios de mortalidade de mudas de menta (Mentha gracilise Menthax villosa) avaliadas com diferentes substratos, após transplante a campo. UTFPR, Dois Vizinhos, 2008.

\begin{tabular}{lc}
\hline Substratos & $\begin{array}{c}\text { Mortalidade } \\
\text { Campo (\%) }\end{array}$ \\
\hline Solo + vermiculi ta + cama-de-aviário & $2 \mathrm{~b}^{\star}$ \\
Esterco bovino + areia + solo & $3 \mathrm{~b}$ \\
Esterco +vermicu ltia+areia & $10 \mathrm{a}$ \\
Organo-mineral Plantmax ${ }^{\circledR} \mathrm{HA}$ & $0,0 \mathrm{~b}$ \\
\hline Média (\%) & 4 \\
\hline
\end{tabular}

*Médias seguidas das mesmas letras, nas colunas, não diferem estatisticamente pelo teste de Tukey, a $5 \%$ de probabilidade.

\section{CONCLUSÃO}

Com base nos resultados obtidos, pode-se concluir que para a produção de mudas de Mentha gracilis e Menthax villosa o substrato Plantmax ${ }^{\circledR} \mathrm{HA}$ é o mais recomendado.

\section{AGRADECIMENTO}

Os autores agradecem a Fundação Araucária e a UTFPR pela concessão da bolsa de estudo.

\section{REFERÊNCIA}

ANDRADE NETO, A.; MENDES, A.N.G; GUIMARÃES, P.T.G. Avaliação de substratos alternativos e tipos de adubação para a produção de mudas de cafeeiro (Coffea arabica L.) em tubetes. Ciência e Agrotecnologia, v.23, n.2, p.270-80, 1999.
CAMPOS, L.A.A. et al. Influência da profundidade de semeadura e substratos no desenvolvimento de sibipiruna (Caesalpina peltophoroides Benth). Científica, v.14, p.101-13, 1986.

FACHINELLO, J.C.; HOFFMANN, A.; NACHTGAL, J.C. Propagação de plantas frutíferas de clima temperado. Pelotas: UFPEL, 1994. 179p.

FERNANDEZ, J.R.C. Efeito de substratos, recipientes e adubação na formação de mudas de mangabeira (Hancornia speciosa Gomes). 2002. 65p. Dissertação (Mestrado - Área de Concentração em Agricultura Tropical) - Universidade Federal de Mato Grosso, Cuiabá.

GAULAND, D.C.S.P. Relações hídricas em substratos à base de turfas sob o uso dos condicionadores casca de arroz carbonizada ou queimada. 1997. 107p. Dissertação (Mestrado - Área de Concentração em Ciência do Solo) - Programa de Pós-Graduação em Agronomia, Universidade Federal do Rio Grande do Sul, Porto Alegre.

GONÇALVES, J.L.M. et al. Produção de mudas de espécies nativas: substrato, nutrição, sombreamento e fertilização. In: GONÇALVES, J.L.M.; BENEDETTI, V. (Eds.). Nutrição e fertilização florestal. Piracicaba: IPEF, 2000. p.309-50.

KÄMPF, A.N. Seleção de materiais para uso como substrato. In: KÄMPF, A.N.; FERMINO, M.H (Eds.). Substratos para plantas: à base da produção vegetal em recipientes. Porto Alegre: Gênesis, 2000. p.139-45. KÄMPF, A.N. Análise física de substratos para plantas. Viçosa: SBCS, 2001. v.26, p.5-7. (Boletim Informativo). LIMA, N.P. et al. Produção de mudas por estaquia de duas espécies de guaco. Horticultura Brasileira, v.21, p.106-9, 2003.

LOPES, P.S.N. Propagação sexuada do maracujazeiro azedo (Passiflora edulis Sims $\mathrm{f}$. favicarpa Deg.) em tubetes: efeito da adubação nitrogenada e substratos. 1996. 52p. Dissertação (Mestrado - Área de Concentração em Fitotecnia) - Universidade Federal de Lavras, Lavras.

MILNER, L. Caracterização, manejo e qualidade de substratos para a produção de plantas. Campinas: Instituto Agronômico, 2002. 122p. (Documento IAC, n.70). MING, L.C et al. Plantas medicinais, aromáticas e condimentares: avanços na pesquisa agronômica. Botucatu: UNESP, 1998. 238p.

PENNINGSFELD, F. Kultursubstrate fur den Gartenbau, besonders in Deutschland; ein Kritischer Überblick. Plant and Soil, v.32, p.937-44, 1983.

PAULUS, D. et al. Substratos na produção hidropônica de mudas de hortelã. Horticultura Brasileira, v.23, p.4850, 2005.

PAULUS, D.; PAULUS, E.; Efeito de substratos agrícolas na produção de mudas de hortelã propagadas por estaquia. Horticultura Brasileira, v.25, p.594-7, 2007.

RIBEIRO, J.F. Cerrado: matas de galeria. Empresa Brasileira de Pesquisa Agropecuária - Centro de Pesquisa Agropecuária dos Cerrados, Planaltina, Distrito Federal, 1998. 164p.

RÖBER, R. Substratos hortícolas: possibilidades e limites de sua composição e uso; exemplos da pesquisa, da indústria e do consumo. In: KÄMPF, A.N.; FERMINO, M.H. (Eds.). Substratos para plantas: a base

Rev. Bras. PI. Med., Botucatu, v.13, n.1, p.90-97, 2011. 
da produção vegetal em recipientes. Porto Alegre: Gênesis, 2000. p.123-38.

SALSAC, I. et al. Nitrate and ammonium nutrition in plants. Plant Physiology and Biochemistry, v.25, p.805-12, 1997. SANTOS, F.R.P. et al. Caracterização físico-química de sete componentes de substratos recomendados para uso em floricultura. Cultura Agronômica, v.11, p.81-92, 2002. SAS INSTITUTE. SAS: user's guide statistics: version 8.0 edition. Cary: SAS, 1999. 956p.
SCHMITZ, J.A.; SOUZA, P.V.; KÄMP, A.N. Propriedades químicas e físicas de substratos de origem mineral e orgânica para o cultivo de mudas em recipientes. Ciência Rural, v.32, p.937-44, 2002.

VIEIRA, A.H. et al. Efeito de diferentes substratos para produção de mudas de freijó-louro Cordia alliodora (Ruiz \& Pav.) Oken. Boletim de Pesquisa, Empresa Brasileira de Pesquisa Agropecuária, n.25, p.12, 1998. 